\title{
A rare case of hemorrhagic cystitis following influenza B infection
}

\author{
I.K.M Wickremasinghe ${ }^{1}$, D.S Kodikaraarachchi ${ }^{2}$
}

\begin{abstract}
Introduction
Hemorrhagic cystitis is defined by the persistent hematuria and lower urinary tract symptoms in a patient who has no other bleeding manifestations or bacterial urinary tract infection. ${ }^{1,2}$. It is caused by viruses, bacteria such as Escherichia coli,chemical toxins, radiation and amyloidosis. ${ }^{1,2}$. Reported causative viruses are influenza A, B, adenoviruses 7,11,21 and 35, papoviruses, polyomaviruses, CMV, JC virus and herpes viruses. Hemorrhigic cystitis following influenza B infection is not common and as far as we know only one such case has been reported in the medical literature to date. ${ }^{3}$
\end{abstract}

\section{Case presentation}

A 5-year old previously healthy boy, presented with rhinorrhea, cough, supra pubic pain and macroscopic hematuria without clots for one day. He had dysuria and increased urinary frequency, without urgency, oliguria or fever. He had no other bleeding manifestations or history of local trauma. On examination, he had no pallor, generalized edema or muscle tenderness. Abdomen was non tender. He had no organomegaly, palpable bladder or masses.Blood pressure was normal. Other system examinations were unremarkable.Urine full report revealed field fullred cells and 1-2/hpfpus cells. Urine for dysmorphic red cells and urine culture were negative. Activated partial thromboplastin time (APTT) was $32.4 \mathrm{sec}$ and International Normalized Ratio (INR) was 1.0.WBC was $4.83 \times 103$, neutrophils $57 \%$ and lymphocytes were $34 \%$. Hemoglobin was $10.8 \mathrm{~g} / \mathrm{dL}$ and platelets were $243 \mathrm{X}$ 103. Blood picture revealed reactive lymphocytes suggestive of viral infection and hypochromic microcytic red cells with pencil cells suggestive of iron deficiency anemia. CRP was $<5 \mathrm{mg} / \mathrm{l}$. Influenza

1.Senior Registrar,

2.Consultant Paediatrician,

Teaching Hospital,Karapitiya, Galle, Sri Lanka.

Corresponding Author:

I.K.M Wickremasinghe

Email: indumini123@gmail.com

(iD https://orcid.org/0600-0002-5644-5426
$B$ rapid antigen test was positive while rapid antigen tests for influenza $A$ and adeno viruses were negative.The result was confirmed by the blood PCR. Mycoplasma antibody titre was less than $1: 40$ on both day 7 and 21 of illness. ASOT was $<200 \mathrm{U} / \mathrm{L}$ on day 2 of illness.

Oseltamavir was commenced on day 2 of illness. He had no macroscopic hematuria after day 3 and microscopic hematuria subsided by day 4 . He developed no features of pneumonia and respiratory symptoms improved by the 6th day.Post discharge follow up was uncomplicated.

\section{Discussion}

Hemorrhagic cystitis is one of the rare complications of Influenza B infection. ${ }^{1,2}$ Only one case of hemorrhagic cystitis following influenza $B$ has been reported in the literature. Robert. et al reported the case of a 31-year- old man who presented with respiratory symptoms and was diagnosed to have influenza B infection on day 6 of illness and developed features of cystitis on 16th day3. However, at the same time his urine culture revealed Escherichia coli ( $\left.>10^{*} 107\right)$, which is a common cause of hemorrhagic cystitis ${ }^{3}$. In contrast, our patient had only influenza B infection.

Therefore, this is the only reported case with hemorrhagic cystitis purely due to influenza B infection.

\section{References}

1. Kliegman RM, Stanton B, St Geme JW, Schor NF. Nelson textbook of Pediatrics(20th edition), Elsevier Inc, 2015

2. Paduch DA. Viral lower urinary tract infections. Curr Prostate Rep. 2007;5(1):40-50. doi:10.1007/ s11918-007-0006-7

3. Robert JA, Marios K, Aeron CH, Katherine K. Uncomplicated Cystitis in an Adult Male Following Influenza B Virus Infection. Am J Case Rep. 2017; 18: 190-193, doi: 10.12659/AJCR.902172. Published online 2017 Feb 22. Accessed December 12, 2019 